\title{
TEACHING HIGHS AND LOWS: EXPLORING UNIVERSITY TEACHING ASSISTANTS’ EXPERIENCES
}

\author{
JENNIFER L. GREEN \\ University of Nebraska-Lincoln \\ jennifer.green@huskers.unl.edu
}

\begin{abstract}
Recent reforms in statistics education have initiated the need to prepare graduate teaching assistants (TAs) for these changes. A focus group study explored the experiences and perceptions of University of Nebraska-Lincoln TAs. The results reinforced the idea that content, pedagogy, and technology are central aspects for teaching an introductory statistics course. The TAs addressed the need for clear, specific guidelines and examples, as well as collaboration between colleagues. The TAs also sought opportunities to enrich their teaching skills and, ultimately, their impact on students' learning. These findings support previous research on graduate TAs and highlight the need for additional exploration of the role graduate statistics TAs play in introductory statistics education.
\end{abstract}

Keywords: Statistics education research; Introductory statistics; Focus group; Qualitative research

\section{INTRODUCTION}

The need to improve the teaching of introductory statistics courses is not a new idea, but with increased professional support, the reform movement has recently gained more attention (Garfield, Hogg, Schau, \& Whittinghill, 2002; Kettenring, Lindsay, \& Siegmund, 2004). Ultimately, statistics instruction is evolving to help create a statistically literate society (Kettenring et al., 2004). Through the "awareness of data in everyday life," students are prepared "for a career in today's 'age of information"” (Rumsey, 2002, \ 2). A careful balance of content, pedagogy, and technology (Moore, 1997) helps introductory courses "move beyond the 'what' of statistics to the 'how' and 'why' of statistics" (Rumsey, 2002, ๆ 7).

However, attaining this balance can be difficult. This new style of teaching places more demands upon instructors, particularly graduate teaching assistants (TAs) (Moore, 2005). The Guidelines for Assessment and Instruction in Statistics Education (GAISE) College Report recommends introductory statistics courses emphasize statistical literacy, foster active learning and develop effective communication of statistical concepts (Garfield et al., 2005). How effectively these recommendations are implemented may be limited by a TA's own statistical knowledge for teaching (Noll, 2007). These demands, in addition to the need to build self-confidence and improve teaching efficiency, emphasize the need to prepare TAs for teaching introductory statistics (Garfield et al., 2002; Noll, 2007; Svinicki, 1995).

Literature explores the training of TAs (Park, 2004) and provides guidelines for enhancing such training programs (Eison \& Vanderford, 1993), emphasizing the need to develop TAs' pedagogical skills (Shannon, Twale, \& Moore, 1998). To help graduate

Statistics Education Research Journal, 9(2), 108-122, http://www.stat.auckland.ac.nz/serj (C) International Association for Statistical Education (IASE/ISI), November, 2010 
TAs develop their teaching abilities, statistics departments at Virginia Tech (Birch \& Morgan, 2005), Penn State University (Harkness \& Rosenberger, 2005) and Iowa State University (Froelich, Duckworth, \& Stephenson, 2005) gradually introduce the TAs to more demanding teaching duties as they progress through their graduate programs. However, the Department of Statistics at the University of Nebraska-Lincoln does not use an incremental approach to teaching; during the first year of a graduate teaching assistantship, a TA is granted sole responsibility of teaching an introductory statistics course.

Initially, University of Nebraska-Lincoln statistics TAs received training from the College of Arts and Sciences, but the training workshop did not adequately prepare the TAs for the discipline-specific demands of teaching introductory statistics. The University of Nebraska-Lincoln Statistics Department, in turn, developed a program to help prepare the TAs for teaching an introductory statistics course. However the department recognized the need to improve the program to better suit TAs' needs, initiating research on the TAs' experiences and perceptions.

Previous studies have explored the perceptions and experiences of graduate TAs in various departments at higher education institutions in the United Kingdom (Muzaka, 2009; Park \& Ramos, 2002), New Zealand (Harland \& Plangger, 2004), and the United States (Belnap, 2005; Volkmann \& Zgagacz, 2004), but few, if any, focus solely on describing the actual experiences of statistics TAs. In general, research on TAs teaching statistics is an area in need of scholarship. The perspectives and experiences of TAs are important for enhancing training and providing appropriate pedagogical preparation and development (Moore, 2005).

The purpose of this focus group study was to bridge the literature and research gap by identifying and recording the various experiences University of Nebraska-Lincoln statistics TAs have while teaching the introductory statistics course. Perceptions and experiences of the TAs were explored through the use of a focus group interview, an individual interview and e-mail protocol writing (Hatch, 2002; Morgan, 1997). The reflections and discussions of the TAs' experiences suggest improvements for the preparation of statistics teaching assistants that, ideally, would enhance the learning experience of introductory statistics students.

The main question guiding this research was: What experiences do statistics TAs at the University of Nebraska-Lincoln have while teaching STAT 218: An Introduction to Statistics? Several sub-questions were also explored: What perceptions do they have about the various aspects of the course? What relationships play a role in their experiences? How do these relationships influence their experiences?

\section{METHODS}

\subsection{FOCUS GROUP STUDY METHODOLOGY}

A TA's experiences teaching introductory statistics cannot be accurately summarized through quantitative data. A qualitative approach helps capture and describe these experiences (Creswell, 1998); in particular, a focus group approach produces in-depth descriptions of the TAs' experiences and perceptions while witnessing their interactions with each other (Krueger, 1988; Morgan, 1997).

In order to understand the experience of teaching introductory statistics, I examined the perceptions and experiences of the graduate TAs who have taught introductory statistics courses at the University of Nebraska-Lincoln. Because TAs interact on a daily basis, focus group studies present "a natural environment where participants are 
influencing and influenced by others-just as they do in real life" (Krueger, 1988, p. 30). Through the use of group interaction, focus groups provide new insights (Morgan, 1997), while keeping the collaborative aspect of teaching authentic.

The main components of a focus group study include "(a) [7-10] people, who (b) possess certain characteristics, [and] (c) provide data (d) of a qualitative nature (e) in a focused discussion" (Krueger, 1988, p. 27). According to Morgan (1997), the whole purpose of "focus groups is to learn about ... participants' experiences and perspectives" (p. 20). This research focused on how the TAs perceived their experiences and interactions while teaching the introductory statistics course. A focus group study was appropriate to answer the research questions and capitalize on the group's interactions:

Everyday forms of communication may tell us as much, if not more, about what people know or experience. In this sense focus groups reach the parts that other methods cannot reach, revealing dimensions of understanding that often remain untapped by more conventional data collection techniques. (Kitzinger, 1995, pp. 299 300)

\subsection{PARTICIPANTS}

For this study, the population of interest was all graduate TAs who are or will be teaching the non-calculus based introductory statistics course, STAT 218, for the University of Nebraska-Lincoln. Instead of assisting someone else with the course, these teaching assistants have sole responsibility for teaching at least one section of STAT 218 each semester. The STAT 218 TAs are responsible for planning and delivering lessons, creating assessments and activities, assigning grades, and completing other duties required of instructors. Each TA is granted the autonomy to teach the course in a manner with which he or she is most comfortable. Ideally, this maximizes the TA's ability to relate the material to the students.

Prior to the introduction of a departmental training program, graduate students who were assigned to teach STAT 218 met one week before the fall semester began. During this week, the TAs attended the College of Arts and Sciences TA Workshop, as well as departmental meetings to help prepare them for the upcoming semester. At the College of Arts and Sciences TA Workshop, TAs learned about general university policy, such as how to address academic dishonesty and how to accommodate students with disabilities. The STAT 218 textbook (Utts \& Heckard, 2004) was also distributed, leaving the TAs with the responsibility of developing a syllabus and, essentially, a course in less than one week. As a beginning TA, I learned a lot at the training, but I did not feel prepared for having sole responsibility of the course.

A week before the fall semester in which this study was conducted, the University of Nebraska-Lincoln Statistics Department implemented a new program to help prepare the TAs for teaching an introductory statistics course. The week-long departmental workshop covered basic logistics of teaching the STAT 218 course. The workshop leaders outlined course-specific expectations, such as holding office hours and developing a syllabus, presented the course management site, Blackboard, discussed how to access the computers in the lab and addressed TAs' questions and concerns. The workshop also provided a scheduled opportunity for experienced TAs to share advice with beginning TAs. Although the TAs appreciated more training, the department recognized the need to improve the program to better suit TAs' needs and initiated research on the TAs' experiences and perceptions.

Ten graduate students who were teaching the introductory statistics course were chosen to participate in the study. These ten TAs, in addition to myself, represented all of 
the STAT 218 instructors from that semester; all had experienced the phenomenon of interest, so none of the TAs were excluded from the study (Morgan, 1997). For purposes of anonymity, the TAs are referred to by pseudonyms: Rachel, Ella, Philip, Jadyn, Abby, Shae, Trevor, Madison, Bailey, and Ali. The participants included both TAs who had taught and TAs who had not taught at least one semester of STAT 218 or an equivalent statistics course before the study began. Most participants were experienced TAs who had completed at least one year of graduate work in statistics (see Table 1). I was also an experienced TA in the second year of my graduate work. At the time of the study, the three new TAs were enrolled in three graduate statistics courses. Each TA had completed at least one statistics course in his or her undergraduate program. The inclusion of the perceptions and experiences of both new TAs and experienced TAs who were at different stages in their graduate programs provided a more complete description of the teaching experience (Silverman, 2005).

Table 1. Participants

\begin{tabular}{lll}
\hline Years completed & Experienced & \# TAs \\
\hline 0 & No & 3 \\
1 & Yes & 6 \\
$2+$ & Yes & 1 \\
\hline
\end{tabular}

\subsection{DATA COLLECTION}

The study did not need to be approved by the Institutional Review Board (IRB), which reviews research projects involving human subjects, because initially the results were intended only for departmental review, and by the time of publication, the data had been de-identified. Halfway through the fall semester, an e-mail informed the ten TAs about the focus group meeting time and location. A week later, nine of the TAs met in the University of Nebraska-Lincoln Statistics Department conference room for the focus group. Each participant was given an information letter and a brief introduction to the general purpose of the study (Krueger, 1988; Morgan, 1997). The TAs sat around a table facing each other and were provided desserts to help create a relaxed, comfortable setting that encouraged interaction (Kitzinger, 1995; Morgan, 1997).

Because I did not want my own teaching experiences to influence the direction of the focus group, I began the session with a broad discussion-starter question (Morgan, 1997): How do you feel this semester has been going so far? No other questions were determined a priori; the informal structure allowed the TAs to discuss topics they found most pressing. My role was solely to help facilitate the meeting, asking probing questions when appropriate (Kitzinger, 1995; Morgan, 1997). The session was tape recorded and transcribed to facilitate accurate note keeping (Krueger, 1988; Morgan, 1997; Weiss, 1994).

The TAs also shared their experiences with me through e-mail. Through the usage of e-mail, I hoped to capture thoughts and perceptions forgotten or unspoken at the focus group (Kitzinger, 1995). Although "the elements of surprise and puzzlement are partly lost," e-mails allow a TA "to respond whenever he or she likes and when time permits" (Cisneros-Puebla, Faux, \& Mey, 2004, 129 ).

Toward the beginning of the fall semester, a link entitled Teaching Assistant Information Exchange was posted on the University of Nebraska-Lincoln Statistics Department webpage. The link directed TAs to a webpage where they could type reflections about their teaching experiences. At the top of the page, a prompt reminded the TAs what they should discuss. The prompt stated, "Reflect on your teaching experiences 
this semester. Please include details about content covered, approaches and activities used, how you felt the class went and any other successes and/or difficulties that occurred." The e-mails were sent to a private account made specifically for this study. After the study was completed, all e-mails were deleted to help maintain a degree of confidentiality. E-mails were sent once a month to the TAs to encourage participation and remind them about the link.

I also conducted an unstructured, open-ended interview with the experienced TA who had completed more than two years of graduate work in statistics (see Table 1). The interview protocol was created from topics discussed at the focus group. Because this TA could not attend the focus group, the interview provided more data and served as a validation check (Morgan, 1997). The TA felt uncomfortable about being tape recorded, so the tape recording was sacrificed for a more open discussion of her feelings, perceptions, and experiences while teaching STAT 218. Table 2 contains details about each of the data collection methods used.

Table 2. Data collection methods

\begin{tabular}{llll}
\hline Method (\#) & \# TAs & Data type & Length \\
\hline Focus Group (1) & 9 & Audio-tape & $1 \mathrm{hr} .15 \mathrm{~min}$. \\
& & Observation notes & \\
E-mails (5) & 4 & Text & $2 \mathrm{months}$ \\
Interview (1) & 1 & Observation notes & $1 \mathrm{hr} .10 \mathrm{~min}$. \\
\hline
\end{tabular}

During the focus group and interview, most of the TAs appeared comfortable sharing their perceptions with me and each other. At first, the tape recorder and open-ended discussion seemed intimidating, but after a few minutes, the discussion was less rigid. Although I feared the TAs would feel as if I were judging them and would share only guarded comments, our familiarity with each other seemed to make them more willing to trust me with their personal thoughts, feelings, perceptions, and experiences.

Limitations During the study, there were a few limitations. Ideally, at least two focus groups would have been conducted to explore changes within the group over time (Morgan, 1997). However, it took longer than anticipated to be informed the study did not need IRB approval, so data collection began later than expected. Although there was not a second focus group, the interview served as a validation and reliability check (Merriam, 2001).

Also, fewer e-mails were received than desired. A few of the e-mails the TAs did send did not go into as much depth as anticipated. It seemed like their comments did not go below the surface; they seemed to be written at a superficial level, where general statements instead of genuine thoughts and perceptions were shared. If the study is continued, the question placed at the top of the e-mail will aim to elicit more in-depth responses. The prompt may also focus on a particular topic discussed during the focus group to get richer descriptions from the TAs. Additionally, incentives may be offered to encourage participation; in this study, e-mail participation was completely voluntary.

\subsection{DATA ANALYSIS}

When analyzing the data, it was important to accurately represent the TAs' experiences and perceptions, not my own. I did not want to superimpose a rubric on the data, so I began with an inductive analysis (Hatch, 2002). After reading the data, I looked for patterns, identifying initial frames of analysis or analyzable parts. During the analysis, 
three main categories emerged: content, pedagogy, and technology. These categories were identified by Moore (1997) as key components of an introductory statistics course.

Tying the literature to the data, I decided to switch to a typological analysis (Hatch, 2002). Using these three typologies, I identified entries that fit into each typology. Within each typology's entries, I searched for main patterns, themes, and relationships. Then the data were coded according to the identified patterns, providing both supporting data and non-examples. After summarizing the relationships among the patterns, I created onesentence generalizations and selected supporting quotes.

In order to ensure valid and reliable conclusions, I paid attention to individuals, as well as the group throughout the whole process (Morgan, 1997). According to Morgan, "Neither the individual nor the group constitutes a separable 'unit of analysis'; instead, our analytic efforts must seek a balance that acknowledges the interplay between these two "levels of analysis"” (p. 60). Comparing the interview observations to the focus group data also allowed me to link findings across the two types of data collection (Morgan, 1997). Furthermore, TAs checked the quotations and interpretations used in the findings, affirming the participants were not inadvertently taken out of context (Merriam, 2001). Because the results were reported to the University of Nebraska-Lincoln Statistics Department, no identifiers were used. Overall, it was important to represent accurately my colleagues' experiences and perceptions, without exposing them to potential bias.

\section{TYPOLOGIES DESCRIBING TEACHING ASSISTANTS' EXPERIENCES AND PERCEPTIONS}

Three main typologies were used to describe the experiences and perceptions of the TAs. One main area of discussion concentrated on support for how to use technology, or "multimedia instructional systems," such as computers and calculators, in an introductory statistics course (Moore, 1997). Another area of discussion focused on content-what is actually taught in the course. The third typology dealt with pedagogy, "the pedagogical (teaching) skills teachers use to impart the specialized knowledge/content of their subject area(s)" (INTIME, 2001, \ 1). Within each of these typologies, various themes emerged (see Table 3), providing a multi-dimensional exploration of the TAs' experiences, relationships, and perceptions.

Table 3. Themes within statistics teaching typologies

\begin{tabular}{ll}
\hline Typology & Theme \\
\hline Support for technology & Microsoft Excel \\
Content & Key points \\
& Teaching assistant's self-image \\
Pedagogy & Teaching skills \\
& Student/teaching assistant interactions \\
& Teaching assistant/teaching assistant interactions \\
\hline
\end{tabular}

\subsection{TYPOLOGY A: SUPPORT FOR TECHNOLOGY}

Microsoft Excel Within the support for technology typology, the use of Microsoft Excel was a main theme. This was the first main topic discussed in the focus group, and it continued to be discussed intermittently throughout the rest of the session. It was also a prevalent topic in the interview and e-mails. The TAs explained they were supposed to incorporate Excel labs into the course, but they were not prepared to do so. Overall, the statistics TAs wanted a more focused direction with Excel. 
The TAs alluded to this generalization through comments expressing criticism and uncertainty. At the beginning of the focus group, Trevor stated, "I think computers are a waste. They slow us down." Shortly afterward, similar comments followed, such as

Jadyn: I actually gave some surveys out, just for my own self, asking people [students] about what they thought and everything was pretty consistent with what people said. They didn't like the labs and thought it was just a waste of time. They actually said they'd rather have a lecture.

Yet, others insisted Excel was not completely wasteful and explained their approaches. Another TA commented,

Shae: I don't focus on it [Excel]. It's not the emphasis, but, hey, you know what, we're just trying to expose them [students] to a few different things. So I tell them to get over it and just endure it.

Philip also mentioned, "It's very beneficial for [teaching] distributions if you can actually plot out the distributions." Either by taking a "what can't hurt you, can only help you" approach or an "it's really useful" approach, some TAs defended the use of Excel, indicating the program itself was not the issue.

Instead, it seemed the TAs' uncertainty with why and how to use the program spurred the negative perceptions. In the discussion, Ella revealed this uncertainty, "After chapter five [linear regression], I don't see a point to doing Excel labs, because I can't come up with anything." Philip affirmed the need for more direction:

Philip: I think it'd help if they [the University of Nebraska-Lincoln Statistics Department] showed us what they want... I mean, they spent all this money to get the computers and ... made a big deal about getting everyone ... on computers. What ... [do they] want us to do, and what should the labs look like?

Overall, the data illustrated that the statistics TAs wanted a more focused direction with Excel. Even though there were mixed attitudes toward the computer program itself, TAs were uncertain about how to incorporate useful Excel labs into the course. They understood they were expected to use Excel, but they did not know how the department wanted them to meet this requirement.

\subsection{TYPOLOGY B: CONTENT}

Key points This uncertainty carried over to discussions about the course content, or the material taught. Unsure of what to teach, new TAs expressed concerns about knowing what is important. One new TA, Bailey, voiced these feelings, and experienced TAs Abby and Philip confirmed the relevance of those feelings.

Bailey: I think the most difficult thing for me in the beginning was ... [that] for the first four chapters there's nothing. And it's just a whole lot of material, and it's just out there .... I think it would be nice to have ... an outline of every single chapter, some idea of what direction to go. Because ... you open up the book, and it's like, "Oh my, [for] the first four chapters what ... am I supposed [to do]?" I mean, I know that there are things that I think are important, but are 
those really the things that are important?

Abby: Our first semester, I don't know how our students learned anything. I mean, I definitely know a lot more now than I did that first [semester]. I was in the same boat as you; we didn't know what to cover, and we didn't have an outline. So I just read the book and covered what I thought was important. Well now I know, but like you [Philip] had said, once you get to later chapters I can be like, "Hey, recall back from chapter four ..." Then you can go back, but since you've [Bailey] never covered the chapters in the book yet, you don't know what's connected. So I just kind of survived and advanced the first semester.

Bailey: I just feel like I did a poor job of covering the first four chapters.

Philip: That's normal.

The TAs thought outlines of each chapter would help them identify key points the department deemed important to cover. However, with more experience teaching and increased familiarity with the material, the TAs felt more confident knowing which topics to teach. An experienced TA, Abby, mentioned, "I actually feel kind of like I know what I'm talking about, sometimes. More so than last year." Yet, this gradual gain of confidence did not help beginning TAs. Instead, the beginning statistics TAs needed clear, specific guidelines to help them develop pedagogical content knowledge (Shulman, 1986) for teaching statistics, such as knowledge of which topics are most important to teach in an introductory statistics course and how such a course can be structured to help convey the relationship among these topics.

Teaching assistant's self-image Confidence and/or uncertainty about the content can affect a TA's perceived image. When I asked an experienced TA, "Why do you think you don't have problem students?," Ali replied, "Do you want me to be honest?" My yes elicited the following response: "I think it is because I have more confidence in the material. It is not that they [new TAs] are not capable of teaching, but more that undergraduate students don't necessarily respect them.”

The stage a TA is at in his or her graduate work can also impact a TA's self-image. Ali continued, "I also think I get more respect because I am a Ph.D. student." The University of Nebraska-Lincoln Statistics Department had a young Ph.D. program; consequently, few students with two or more years of graduate work in statistics were available to teach the many sections of STAT 218 offered each semester. Jadyn, an experienced TA with one year of graduate work completed, advised a new TA, "Don't let them [students] take advantage of you. They think they can get away with a lot because they know we're TAs." Yet, Shae considered contrasting viewpoints, from a student's perspective:

Shae: As a student sometimes I wonder ... if they're sitting there ... [thinking] they're getting ... three credit hours for this class, and it's completely taught by a TA. And I've had students put on their evaluations, "I can't believe a TA is teaching this class." Not that they were ripping on me or anything, but just the fact that a TA instead of a full professor is teaching this class to them.... But in some ways, I think some students appreciate the fact that, I don't know, maybe I'm a little easier than a professor would be ... I kind of accommodate to them, I think, a little bit more sometimes than professors do.... [S]o, I mean, I see both sides to it. 
TAs serve dual roles as teachers and students (University of Pittsburgh, 2003), and they believed their confidence in the course material, or lack thereof, as well their different stages in the graduate program, influenced their images. The TAs did not necessarily lack the appropriate subject matter knowledge, but instead the pedagogical content knowledge (Shulman, 1986) for teaching statistics. By sharing comments about how they thought students perceived them, the TAs seemed to indicate that although their role as teachers distinguished them from other students, their self-images undermined this role; they were not undergraduate students, but they were not professors either. Overall, the TAs confirmed that their uncertainty about the course content coupled with their perceived images, are inevitable aspects of the teaching experience.

\subsection{TYPOLOGY C: PEDAGOGY}

Teaching skills Other aspects of the teaching experience focused on how to best convey the course content. More specifically, these concerns stemmed from a sense of responsibility for their students' learning. Ali shared, "I did not have any previous teaching experience, so I was terrified when I first started." She also divulged, "I was afraid I would not explain things well enough." Even the TAs who had previously taught during their undergraduate experience shared the same fears as those who had not.

Trevor: Well, we had four of us that were education majors in undergrad, so we got out of it [micro-teaching lesson].

Abby: Oh, that's why, ya.

Philip: And I had no idea of teaching.

Abby: Nobody had any idea of what they were teaching.

Shae: It [the first time teaching STAT 218] was a horrible semester.

To some TAs, developing their teaching skills was the hardest challenge. According to an unidentified TA, most challenges revolved around how to fine-tune the teaching skills already in place: "My greatest difficulties have been trying to flow clearly through the information I am teaching and making sure I have enough material to cover during the period. I have had problems with people sleeping, but I guess that is pretty normal." This TA recognized room to develop better teaching skills, but acknowledged this development was not an easy task. In a struggle to find the best teaching strategies, Jadyn conceded,

Jadyn: I think one of the struggles is, I don't know,... I don't want to be too lenient and spend too long on stuff. But it seems like then they start complaining that they don't understand it. But at the same time,... it's ... hard ... to draw the line [between] whether they don't really understand it or they're just being lazy and they're complaining because they only come to class one day a week... I don't know ... I just ... need to work on explaining stuff, but I'm just kind of like, "It's there, and I don't know how to explain it." I mean, I just tell it to them and I'm like, I don't know.

By sharing these teaching struggles, the TAs exhibited the desire to develop as educators, aiming to meet the needs of their students in the best way. In other words, this desire was fueled by their concern for their students' learning. The TAs wanted to enrich their teaching skills and, ultimately, their impact on students' learning. 
Student/teaching assistant interactions Part of the teaching experience involved the relationships formed between TAs and their students, as well as their impact on one another. The TAs seemed to take these relationships seriously. In fact, Abby felt guilty about not knowing the students' names:

Abby: With 60 students, ... I think I should have made ... more of a point to have learned their names by now. Because I hate when I know some, but then I look at someone, and I have no idea what their name is. Sometimes I think they take it personally, like, "You know their name, but you don't know mine."

This insistence on learning the students' names illustrated the TAs' desire to also view students individually, rather than only collectively.

Yet, the relationship did not seem to extend solely in one direction. Some students also initiated relationships. According to Philip, "Some of my summer students just wanted to sit around and talk. They'd just sit there and talk to me after class and ask me random things." This extra initiation built relationships beyond the scope of the course material. However, other relationships were not necessarily perceived the same way:

Shae: I think fall semester students are $a$ lot more fun than spring semester students, just in general. I don't know what it is about spring semester... They were fine, like we got along fine, but they just weren't as fun. I think they just wanted to be out of there.

How the TAs perceived the students' attitudes affected the TAs' attitudes and, ultimately, their relationships with the students. Essentially, the interaction between the students and the TAs played a key role in their relationships. How one person responded seemed to influence the other. For instance, when commenting about a chapter in the textbook, Ella shared, "Personally, I think that it is one of my weaker chapters, and I am just not enthused. I always feel that if I am not enthused, my students must feel ten times worse." Ella claimed a lack of enthusiasm affected the students, indicating a one-directional relationship (TA $\rightarrow$ Students).

Yet, how the students reacted also affected the TAs (Students $\rightarrow$ TA):

Abby: This semester, one of my classes I really like, and the other one I really don't like. And I think it's just because I get frustrated because they just sit there and don't respond or laugh or do anything.... But my other class, then, are really talkative and interact with me, and that makes the class go a lot more smoothly.

Overall, these experiences illustrated students and statistics TAs have a reciprocal relationship. Through interactions with each other, the students and TAs mutually influenced their relationships and how those relationships were perceived.

Teaching assistant/teaching assistant interactions With the pressures of teaching, the TAs also developed relationships with each other. When describing the pressures, a TA stated, "Teaching your own class is overwhelming at first, because you control everything." In response to these responsibilities, the TAs cooperatively shared teaching strategies and techniques for STAT 218. Although all of the TAs worked together, the crux of this cooperative effort depended on the help experienced TAs provided to new 
TAs. Responding to what was most beneficial, Madison, a new TA, shared, "It's really nice being able to have ... other past TAs to get information or get examples and stuff." Abby concurred:

Abby: Last year ... I worked with [a second year TA].... [W]e prepared classes together because we ... had to teach the same material. So, having a second year student working with me ... I definitely think that was beneficial for me. Because I think, the mentoring thing, like pairing someone up with a second year student would be good.

Teaching STAT 218 is a cooperative effort, dependent upon the interactions between the TAs. The demands of teaching the statistics course well and the common experiences shared by the TAs created a supportive environment, conducive to collaboration. Inherently, these elements, in addition to other relationships and teaching skills, helped define the statistics TAs' teaching experiences and portray their perceptions (see Table 4).

Table 4. Generalizations within statistics teaching typologies and themes

\begin{tabular}{lll}
\hline Typology & Theme & Generalization \\
\hline $\begin{array}{l}\text { Support for } \\
\text { technology }\end{array}$ & Microsoft Excel & $\begin{array}{l}\text { Statistics teaching assistants want a more focused } \\
\text { direction with Excel. }\end{array}$ \\
Content & Key points & $\begin{array}{l}\text { Beginning statistics teaching assistants need clear, specific } \\
\text { guidelines to help them develop pedagogical content } \\
\text { knowledge for teaching statistics. }\end{array}$ \\
& $\begin{array}{l}\text { Teaching assistant's } \\
\text { self-image }\end{array}$ & $\begin{array}{l}\text { Confidence and/or uncertainty about the content affect a } \\
\text { statistics teaching assistant's self-image. }\end{array}$ \\
Pedagogy & $\begin{array}{l}\text { Teaching skills } \\
\text { Statistics teaching assistants want to enrich their teaching } \\
\text { skills and, ultimately, their impact on students' learning }\end{array}$ \\
& $\begin{array}{l}\text { Student/teaching } \\
\text { assistant interactions }\end{array}$ & $\begin{array}{l}\text { Students and statistics teaching assistants have a reciprocal } \\
\text { relationship. }\end{array}$ \\
& $\begin{array}{l}\text { Teaching assistant/ } \\
\text { teaching assistant } \\
\text { interactions }\end{array}$ & $\begin{array}{l}\text { Teaching STAT 218 is a cooperative effort, dependent } \\
\text { upon the interactions between the statistics teaching } \\
\text { assistants. }\end{array}$ \\
\hline
\end{tabular}

\section{DISCUSSION AND CONCLUSION}

Because "the case for substantial change in statistics instruction is built on strong synergies between content, pedagogy, and technology," (Moore, 1997, p. 123) recent reforms in statistics education have placed more demands on statistics instructors, particularly graduate TAs (Moore, 2005). In the University of Nebraska-Lincoln Statistics Department, the TAs have felt the pressure of these demands, as well as other obligations common to TAs in other disciplines (University of North Carolina, 1992; University of Pittsburgh, 2003). With these pressures and the TAs' significant role in undergraduate education, "it is important to train TAs, not only to insure high quality classroom instruction but also to prepare them for teaching careers when they finish their degrees" (University of North Carolina, 1992, p. 1). 
Typically, many TAs who are teaching a college course for the first time need their tasks defined as specifically as possible:

All new TAs experience anxiety about their jobs because it is usually the first time they assume the role of teacher after having been students all their lives. Moreover, many new TAs simply don't know what their basic responsibilities will be. (University of North Carolina, 1992, p. 1)

The University of Nebraska-Lincoln statistics TAs felt this anxiety. However, by providing beginning TAs with clear, specific responsibilities and examples, departments can help alleviate TA anxiety and improve the quality of instruction (University of North Carolina, 1992). Statistics departments, in particular, need to provide explicit guidance to TAs about how to utilize technology effectively to enhance course content. In addition, beginning statistics TAs need specific directives to help them develop pedagogical content knowledge for teaching statistics; knowledge of which topics are most important to teach in an introductory statistics course and how such a course can be structured to help convey the relationship between these topics is formed through experience. However, ongoing support and mentoring can help ease a beginning TA's transition from student to instructor.

Departments can also encourage a sense of community among the TAs. The University of Pittsburgh (2003) claims it is important to provide TAs "with a collaborative atmosphere where they can air concerns, get supportive feedback, and share what works and what doesn't" ( $₫ 4$ ). In response to pressures that arose, the University of Nebraska-Lincoln statistics TAs formed supportive relationships, interacting with each other to improve their teaching strategies and skills. Although the TAs' interactions were informal and self-initiated, such interactions can be formalized and used to provide ongoing support for TAs. Specifically, these interactions can be formalized by pairing beginning TAs with both a faculty member and an experienced TA; such relationships can provide TAs with a built-in support system and promote a collaborative environment. Ideally, a TA's relationship with his or her faculty mentor would continue throughout the TA's teaching career, as would relationships formed with his or her peers.

Courses designed to prepare teachers of introductory statistics are another avenue to allow TAs to reflect upon and engage in ongoing discussions about the teaching and learning of statistics. At the University of Minnesota, Garfield and Everson (2009) used the GAISE guidelines to design a course to help teachers become knowledgeable about "curriculum, learners, and knowledge of teaching (both in general and specifically, of teaching statistics)" ( $(7)$ ). Another course recently developed (partially as a response to the findings of this study) by the University of Nebraska-Lincoln Statistics Department aims to help TAs develop effective strategies for teaching statistical concepts aligned with the GAISE guidelines. However, the course centers on the use of "writing to learn" strategies as one possible approach for developing statistical literacy and critical thinking skills. Although it is assumed TAs have appropriate subject matter knowledge, they may be lacking the pedagogical content knowledge needed to provide reform-based instruction in an introductory statistics course. Courses, such as those developed by Garfield and Everson and the University of Nebraska-Lincoln Statistics Department, can help prepare TAs to address potential challenges associated with teaching an introductory statistics course in accordance with the GAISE guidelines.

Although these findings support suggestions provided in previous literature about how to prepare TAs for teaching (University of North Carolina, 1992) and how to assess departmental TA training programs offered (Eison \& Vanderford, 1993), the University of Nebraska-Lincoln statistics TAs' experiences and perceptions illustrate TA preparation, perhaps generally but particularly in statistics departments, is still an issue that needs to be 
addressed. Given the inherent importance of developing educated consumers of statistics (Garfield et al., 2005; Utts, 2003) and preparing future teachers of statistics, it seems critical that departments offer TAs the support necessary for developing the pedagogical content knowledge needed to teach introductory statistics courses effectively. Graduate TAs play a critical role in the statistical education many undergraduate students receive, yet research on these TAs is sparse. Specifically, further research should explore and document how changes to TA preparation systems already in place impact not only TAs' experiences, perceptions, and pedagogical content knowledge for teaching statistics, but also their students' learning. The study's findings demonstrate the current relevance of such research and highlight the need for additional exploration of the role graduate statistics TAs play in introductory statistics education.

\section{ACKNOWLEDGEMENTS}

I am extremely grateful for the teaching assistants who participated in the study and openly shared their thoughts, perceptions, and experiences. I would like to thank Erin Blankenship, Martin Frenzel, Denise Green, and Wendy Smith for their thoughtful feedback and comments on earlier drafts of this manuscript. I also appreciate the insightful suggestions provided by the editors and reviewers.

\section{REFERENCES}

Belnap, J. K. (2005). Putting TAs into context: Understanding the graduate mathematics teaching assistant (Unpublished doctoral dissertation). University of Arizona, Tucson, AZ.

Birch, J. B., \& Morgan, J. P. (2005). TA training at Virginia Tech: A stepwise progression. The American Statistician, 59(1), 14-18.

Cisneros-Puebla, C. A., Faux, R., \& Mey, G. (2004). Qualitative researchers-Stories told, stories shared: The storied nature of qualitative research. An introduction to the special issue: FQS interviews I. Forum: Qualitative social research, 5(3), Art. 37. [Online: http://www.qualitative-research.net/fqs-texte/3-04/04-3-37-e.htm\#g32 ]

Creswell, J. W. (1998). Qualitative inquiry and research design: Choosing among five traditions. Thousand Oaks, CA: Sage.

Eison, J., \& Vanderford, M. (1993). Enhancing GTA training in academic departments: Some self-assessment guidelines. In D. L. Wright \& J. P. Lunde (Eds.), To improve the academy: Resources for faculty, instructional, and organizational development (Vol. 12, pp. 53-68). Stillwater, OK: New Forums Press.

Froelich, A. G., Duckworth, W. M., \& Stephenson, W. R. (2005). Training statistics teachers at Iowa State University. The American Statistician, 59(1), 8-10.

Garfield, J., Aliaga, M., Cobb, G., Cuff, C., Gould, R., Lock, R., ... Witmer, J. (2005). Guidelines for assessment and instruction in statistics education (GAISE) college report. Alexandria, VA: American Statistical Association.

[Online: http://www.amstat.org/education/GAISE/GAISECollege.htm ]

Garfield, J., \& Everson, M. (2009). Preparing teachers of statistics: A graduate course for future teachers. Journal of Statistics Education, 17(2).

[Online: http://www.amstat.org/publications/jse/v17n2/garfield.html ]

Garfield, J., Hogg, B., Schau, C., \& Whittinghill, D. (2002). First courses in statistical science: The status of educational reform efforts. Journal of Statistics Education, 10(2).

[Online: http://www.amstat.org/publications/jse/v10n2/garfield.html ] 
Harkness, W. L., \& Rosenberger, J. L. (2005). Training graduate students at Penn State University in teaching statistics. The American Statistician, 59(1), 11-13.

Harland, T., \& Plangger, G. (2004). The postgraduate chameleon: Changing roles in doctoral education. Active Learning in Higher Education, 5(1), 73-86.

Hatch, J. A. (2002). Doing qualitative research in education settings. Albany: State University of New York Press.

INTIME. (2001). Pedagogia [Pedagogy]. Integrating New Technologies into the Methods of Education: The Model.

[Online: http://www.intime.uni.edu/model/Portuguese Model/teacher/teac4.html ]

Kettenring, J., Lindsay, B., \& Siegmund, D. (Eds.). (2004). Statistics: Challenges and opportunities for the twenty-first century (National Science Foundation Report). Washington, DC: National Science Foundation.

[Online: http://www.stat.psu.edu/news/reports/NSFAug2004.pdf ]

Kitzinger, J. (1995). Qualitative research: Introducing focus groups. British Medical Journal, 311(7000), 299-302.

Krueger, R. A. (1988). Focus groups: A practical guide for applied research. Newbury Park, CA: Sage.

Merriam, S. B. (2001). Qualitative research and case study applications in education (Rev. ed.). San Francisco: Jossey-Bass.

Moore, D. S. (1997). New pedagogy and new content: The case of statistics. International Statistical Review, 65(2), 123-165.

Moore, D. S. (2005). Preparing graduate students to teach statistics: Introduction. The American Statistician, 59(1), 1-3.

Morgan, D. (1997). Focus groups as qualitative research $\left(2^{\text {nd }}\right.$ ed.). Thousand Oaks, CA: Sage.

Muzaka, V. (2009). The niche of graduate teaching assistants (GTAs): Perceptions and reflections. Teaching in Higher Education, 14(1), 1-12.

Noll, J. A. (2007). Graduate teaching assistants' statistical knowledge for teaching (Unpublished doctoral dissertation). Portland State University, Portland, OR.

Park, C. (2004). The graduate teaching assistant (GTA): Lessons from North American experience. Teaching in Higher Education, 9(3), 349-361.

Park, C., \& Ramos, M. (2002). The donkey in the department? Insights into the graduate teaching assistant (GTA) experience in the UK. Journal of Graduate Education, 3(2), $47-53$.

Rumsey, D. J. (2002). Statistical literacy as a goal for introductory statistics courses. Journal of Statistics Education, 10(3).

[Online: http://www.amstat.org/publications/jse/v10n3/rumsey2.html ]

Shannon, D. M., Twale, D. J., \& Moore, M. S. (1998). TA teaching effectiveness: The impact of training and teaching experience. The Journal of Higher Education, 69(4), 440-466.

Shulman, L. S. (1986). Those who understand: Knowledge growth in teaching. Educational Researcher, 15(2), 4-14.

Silverman, D. (2005). Doing qualitative research: A practical handbook (2 ${ }^{\text {nd }}$ ed.). Thousand Oaks, CA: Sage.

Svinicki, M. (1995). A dozen reasons why we should prepare graduate students to teach. Journal of Graduate Teaching Assistant Development, 3(1), 5-8.

University of North Carolina, Center for Teaching and Learning. (1992). TAs and professors as a teaching team: A faculty guide to TA training \& supervision. Chapel Hill, NC: Author.

[Online: http://ctl.unc.edu/tasandprofessors.pdf ] 
University of Pittsburgh, Center for Instructional Development and Distance Education. (2003). Teaching practicum models strategies for teaching assistants. Teaching Times, October.

[Online: www.cidde.pitt.edu/sites/default/files/tt/archives/2003 oct/practicum.htm ]

Utts, J. (2003). What educated citizens should know about statistics and probability. The American Statistician, 57(2), 74-79.

Utts, J. M., \& Heckard, R. F. (2004). Mind on statistics ( $2^{\text {nd }}$ ed.). Belmont, CA: Thomson.

Volkmann, M. J., \& Zgagacz, M. (2004). Learning to teach physics through inquiry: The lived experience of a graduate teaching assistant. Journal of Research in Science Teaching, 41(6), 584-602.

Weiss, R. S. (1994). Learning from strangers: The art and method of qualitative interview studies. New York: Free Press.

JENNIFER L. GREEN

Department of Statistics

340 Hardin Hall North

University of Nebraska-Lincoln

Lincoln, NE 68583-0963 